Témoigner Témoigner. Entre histoire et mémoire

Getuigen Revue pluridisciplinaire de la Fondation Auschwitz

$124 \mid 2017$

La musique dans les camps

\title{
War dogs (Todd Philips)
}

War dogs : des chiens fous dans l'instabilité géopolitique

\section{Gorik de Henau}

\section{Q OpenEdition}

\section{Journals}

\section{Édition électronique}

URL : https://journals.openedition.org/temoigner/5673

DOI : $10.4000 /$ temoigner.5673

ISSN : 2506-6390

\section{Éditeur :}

Éditions du Centre d'études et de documentation Mémoire d'Auschwitz, Éditions Kimé

\section{Édition imprimée}

Date de publication : 2 avril 2017

Pagination : $9-12$

ISBN : 978-2-930953-00-7

ISSN : 2037-4183

\section{Référence électronique}

Gorik de Henau, «War dogs (Todd Philips)», Témoigner. Entre histoire et mémoire [Online], 124 | 2017,

Online op 30 novembre 2021, geraadpleegd op 01 décembre 2021. URL: http://

journals.openedition.org/temoigner/5673 ; DOI: https://doi.org/10.4000/temoigner.5673 


\section{WAR DOGS (TODD PHILIPS)}

FILM Dat de buitenlandse politiek van de Verenigde Staten soms via kronkelwegen verloopt, is lang geen staatsgeheim. Maar het komt niet vaak voor dat het onderwerp op indirecte wijze wordt aangekaart in een Hollywoodfilm met een groot budget en bekende acteurs.

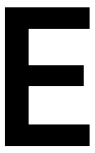

en half vervallen betonnen woonkazerne. Een jongeman wordt uit de kofferbak van een auto gehaald door een stel gemaskerde mannen, die hem vervolgens verrot schoppen. Hij roept herhaaldelijk: 'I don't understand, I don't speak Albanian.' Waarop een van de mannen een pistool op zijn voorhoofd richt en in perfect Engels zegt: 'Do you understand now?' Deze scène, het begin van de film War Dogs, is meteen een perfecte metafoor voor het geheel. Het betreft het door waargebeurde feiten geïnspireerde verhaal van twee jongemannen die zich in een dol avontuur storten, maar niet goed beseffen waar ze aan begonnen zijn.

Efraim Diveroli en David Packouz zijn twee wiet rokende twintigers die een goudmijn ontdekken als ze

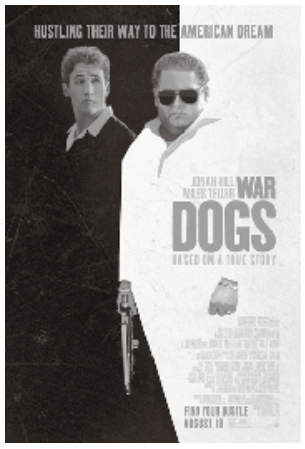
gaan bieden op openbare aanbestedingen van het Amerikaanse ministerie van Defensie. Met groeiend succes bewegen ze zich op de markt van wapens, munitie en ander oorlogstuig, en in geen tijd zwemmen ze in het geld. Maar als ze een miljoenencontract binnenhalen voor de levering van munitie aan het Afghaanse leger, lijkt het of ze zich overtild hebben en beginnen hun problemen pas echt. Een en ander werd ingegeven door Arms and the Dudes, een artikel dat journalist Guy Lawson schreef voor het magazine Rolling Stone en dat hij later zelf tot een boek uitwerkte.

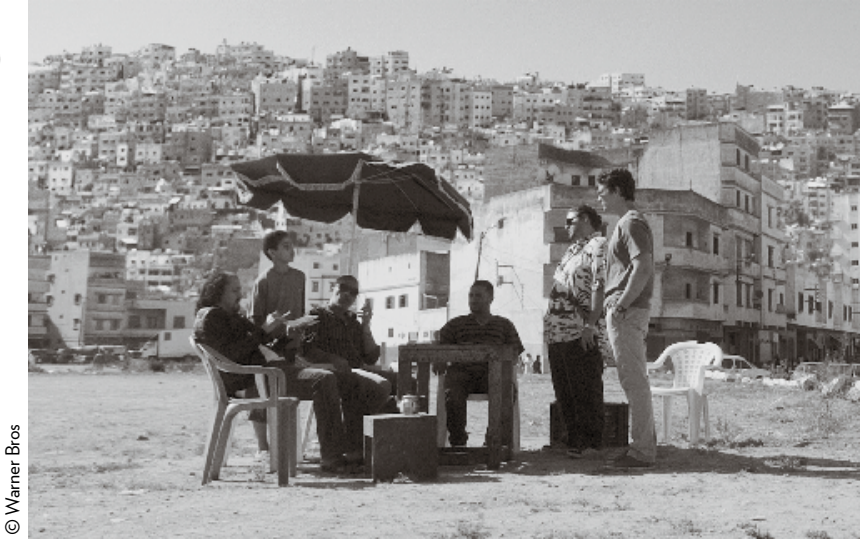

'War dogs' (oorlogshonden) is oorspronkelijk een denigrerende term waarmee wordt verwezen naar zakenmensen die als tussenpersonen geld verdienen aan de oorlog zonder ooit een wapen in handen te nemen of een voet op het strijdtoneel te zetten. In de film wordt hij door de protagonisten expliciet opgeëist als een eretitel. Een opvallend detail is dat beide mannen van Joodse afkomst zijn. Efraim draagt duidelijk zichtbaar een hals-

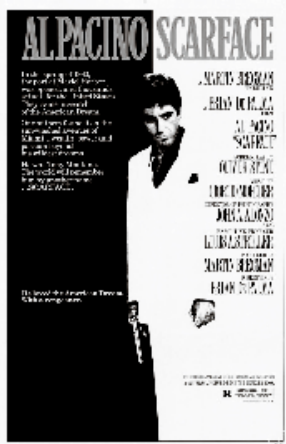
ketting met het Joodse symbool 'chai' (leven). De twee jongemannen ontmoeten elkaar weer voor het eerst sinds hun schooltijd bij een Joodse uitvaartdienst. En in de loop van het verhaal halen ze sporadisch herinneringen op aan hun tijd op de jesjiva of Talmoedschool. In wat volgt, speelt hun afkomst geen rol van betekenis, of het moet zijn dat voortdurend op impliciete wijze de morele dimensie van het gebeurde aan de orde wordt gesteld.

De film mag dan worden gepresenteerd als een waargebeurd relaas - 'based on a true story' lezen we bij het begin - maar de satirische elementen krijgen al snel de overhand. Via de lotgevallen van Diveroli en Packouz krijg je een ironische versie van de American dream. De twee willen koste wat het kost rijk worden; hoe dat gebeurt, is niet zo belangrijk. De promotionele slagzin van de film luidt niet voor niets: 'Hustling their way to the American Dream.' Diveroli •.. 


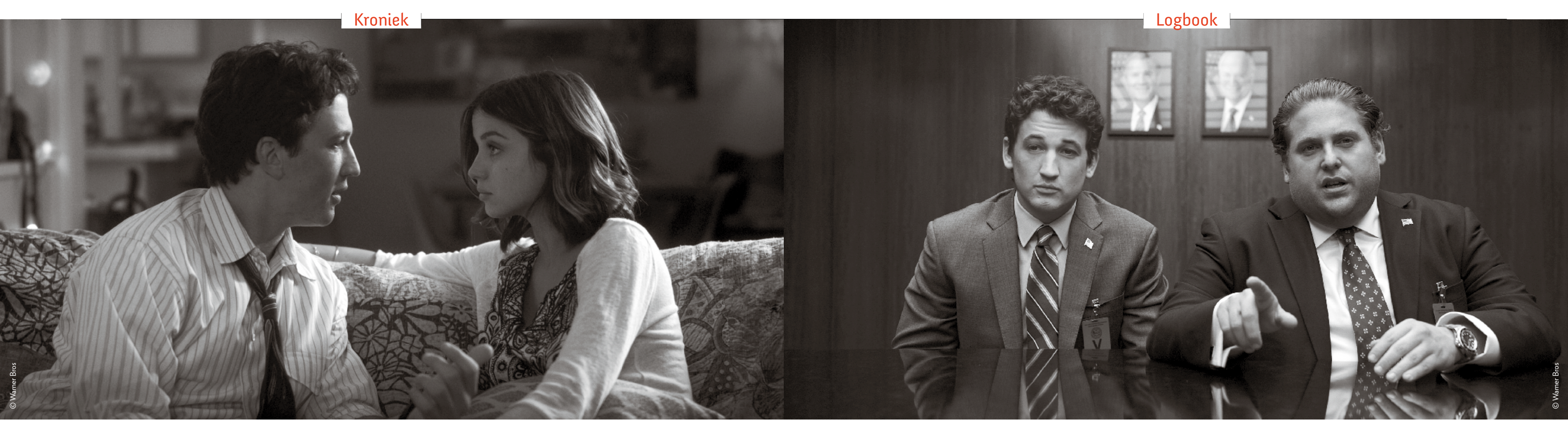

-. spiegelt zich aan Tony Montana, Al Pacino's personage Scarface (Brian De Palma, 1983). Dat is een remake van de gelijknamige, mythische gangsterfilm uit 1932

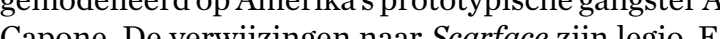
Capone. De verwijzingen naar Scarface zijn legio. E is niet alleen de lijk appelleert an dijn zan de rewsicon In het kantoor van hun bedrijf ALY hangt een groo gen veralogen verwijzen de twee habaldelijk naar wat ze hu Vots noenen.

Voorts kunje veel parallellen trekken met het werk van Martin Scorsese, die geldt als de chroniqueur van crimineel Amerika en wiens films altijd een ster Casino, Gangs of New York en The Departed Als de casino, Gans of Clatie tussen beide mannen onder druk komt te staan, roept het verhaal soms de gespannen verhouding op ter satirische elementen doen dan weer de uitzinnThe Wolf of Wall Street, waarin Scorsese de uitwase ho van het dolgedraaide kapitalisme op de korrel neemt (nill) Jil n. deelt War Dogs trouwens de acteur Jonah van . Letbijver cocaïneschuiven tussen het zakendoen door en een hilarisch AEY-sollicitatiegesprek waarbij een al te ijveDe kern meteen wordt doorgestuurd.

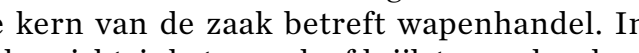
moreel opzicht. is het geoorloofd rijk te worden doo een oorlogsmachine teolicndie ontelbare onschuldige slij brens maakt en hele landen weer naar de steenje eom overtuiginge naarvoor tegen je eigen ov tuigngen en principes moet ingaan? Of om het met Mor de mens baten zo hij de gehele wereld won, en aan zijn

De film volgt een klassiek stramien. We beginnen inet een flash forward, namelijk de hoger geschetste scène in medias res, en keren dan terug naar hoe het allemaal begon. Na de gestage opbouw van het conHet geheel wordt viste en viteind Het geheel wordt verteld vanuit het perspectief van David, die de toesch streeks aanspreekt. Het is een vertrouwd verhaal over de opkomst en ondergang van een personage, waarvan we ons als toeschouwer afvagen of hij intussen iets heeft geleerd. De echte David Packouz speelt trouwens verluidt heeft hij zijn leven war de rils. Naar komt hij nu aan de kost als uitvinder en zakenman. Hij
zou in onmin leven met zijn vroegere zakenpartner zou in onmin leven met zijn vroegere zakenpartner
Efraim Diveroli, de enige die daadwerkelijk een gevangenisstraf uitzat.

genisstraf uitzat. Daarnaast bevathetver confidence men-thematiek, waarbij de daders trachten lemand op te lichten door eerst zijn/haar vertrouwe te winnen. Het conmen-verhaal hoortzelf thuis binnen het picareske genre, in de littratur bekend als schelwe num. Dergelijke verhalen zijn populair omdat we nu een men met bedrog en oplichterij, er gaat een vreemde d t dat het slach inceris zoals gebrilke Ook het antagonistische duo in de hounsta Ook het antagonistische duo in de hoofdrol is een dankbaar dramatisch gegeven, op het witte doek vaak onschreven met de term buddy movie. De geboren alonan pragmatisch en larger thanlife. Davidisdegoedbedoelende viend die zich op sleeptouwlat nemen door het snelle geldgewin en twijfels over zijn eigen professio-

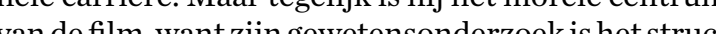
vare
In dergelijke films is de relatie van de protagonist met zijn vrouw en eventueel kinderen een zwak punt; ze

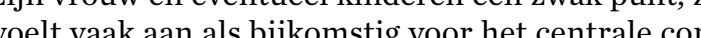
flict of zelfs alsen to gift a Hier is ze net bepalend, want vanwe zijn vouw lo De leugen wordtzo een thema, nict alleen tegenover anderen (zogenaand 'om hen te beschen teg'), ook tegenover zichzelf

le drama wordt gespeeld op Dit persoonlijke morele drama wordt gespeeld op 2008, en meoplitick toned, nan

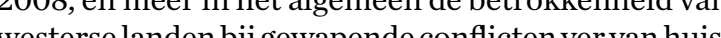
Voor de goede verstander wordt het morele bankTot roet van een hele generatie politici (George Bush jr. Dick Cheney en anderen) bredut over het schern

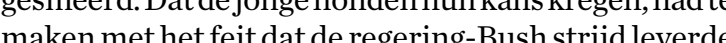

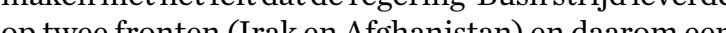
twe twee fronten (lrak en Afghanistan) en daarom een tweesporenbeleid voerde. Enerzijds werden bepaalde vébedrijuen, oorderzijds werden bevriende aan prikelijk vorzich van oorlogstuig. De wapenindustrie kelijk voorzien van oorlogstuig. De wapenindustrie wordt vo dan ook has voord 
-. montage van authentieke nieuwsbeelden waarin we Amerikaanse politici handjes zien schudden met leiders van landen in oorlog. In de razendsnelle opeenvolging herkennen we de voormalige Afghaanse president Hamid Karzai, wiens regeerperiode nu vooral wordt geassocieerd met de escalerende strijd tegen de taliban en allerhande corruptieschandalen.

De oorlogseconomie wordt voorgesteld als business as usual, want wapenhandel is een sector als een andere. De economie moet draaien, zodat de Amerikaanse burgers werk hebben en geen vreemde dingen gaan doen in het stemhokje als er weer eens verkiezingen aankomen. De wetgeving en reglementering ter zake worden afgedaan als een doekje voor het bloeden; een beetje zakenman kan ze makkelijk omzeilen en het Amerikaanse leger en het ministerie van Defensie kijken graag de andere kant uit. De manier waarop openbare aanbestedingen voor militaire uitgaven worden georganiseerd wordt gehekeld als een lachertje. Ook het Amerikaanse exceptionalisme (de overtuiging dat het Amerikaanse volk vanwege zijn geschiedenis een bijzonder positie inneemt) krijgt een veeg uit de pan. Als beide wapenhandelaren aankomen op een luchthaven in het Midden-Oosten gaat Diveroli bij de douane niet in de rij zijn beurt afwachten, maar duwt de omstanders uit de weg met de woorden 'I have to go first, I'm American.'

War Dogs is niet de eerste film waarin een dergelijke thematiek aan bod komt. Three Kings (David O. Russell, 1999) is het fictieve, satirische verhaal van Amerikaanse soldaten die in de nasleep van de Eerste Golfoorlog in de Iraakse woestijn op zoek gaan naar goud. In Lord of War (Andrew Niccol, 2005) speelt Nicolas Cage een op Viktor Bout geïnspireerde wapenhandelaar die zonder de minste scrupules wapentuig levert aan dictators en strijdende partijen over de hele wereld. Charlie Wilson's War (Mike Nichols, 2007) is het gedramatiseerde relaas van de activiteiten van de Amerikaanse senator Charlie Wilson in Afghanistan. Tijdens de Sovjetbezetting van dat land hielp hij met de hulp van de CIA de moedjahedien bewapenen, waardoor hij ongewild mee aan de wieg stond van de latere taliban. En in het ook op waargebeurde feiten gebaseerde Rock the Kasbah (Barry Levinson, 2015) ontdekt een Amerikaanse impresario in Afghanistan een zangeres met een gouden stem, die hij vervolgens begeleidt tijdens een muzikale talentenjacht. Interessant in dit verband is ook American Gangster (Ridley Scott, 2007), over de geopolitieke implicaties van de drugshandel in de Verenigde Staten. Ten tijde van de Vietnamoorlog bevoorraadt de protagonist van de film zich in Thailand en hij laat de drugs overkomen via de vliegtuigen waarmee de lichamen worden gerepatrieerd van omgekomen Amerikaanse soldaten.

Regisseur en coscenarist Todd Philips stond tot nog toe bijna uitsluitend bekend als de maker van een reeks bromance-films: verhalen waarin mannen op zoek zijn naar zichzelf via zogenaamd 'viriel' gedrag (dronkenschap, baldadigheden, uit de hand gelopen practical jokes). Denk daarbij aan Road Trip, Old School en de in financieel opzicht bijzonder succesvolle Hangover-trilogie. Met War Dogs, zijn eerste film met een volwassen onderwerp, lijkt hij te mikken op grotere artistieke geloofwaardigheid. Ondanks de onmiskenbaar satirische insteek levert hij een film af waarin het entertainmentkarakter uiteindelijk het belangrijkst blijkt. Maar hij stelt wel kwesties aan de orde die zelden aan bod komen in films voor het grote publiek. In tegenstelling tot veel Amerikaanse actiefilms, waarin de wereld zonder enige context wordt voorgesteld als een speeltuin voor het Amerikaanse leger en/of geheime diensten, wordt Amerika's rol hier voor een keer niet afgedaan als 'te moeilijk voor de gemiddelde kijker' of 'te politiek gevoelig'.

Gorik de Henau $\rightarrow$ War Dogs van Todd Philips (2016)

Met: Jonah Hill (Efraim Diveroli), Miles Teller (David Packouz), Bradley Cooper (Henry Girard), Ana de Armas (Iz) e.a. 114 minuten.

\section{Bibliografie}

Guy Lawson, 'The Stoner Arms Dealers: How Two American Kids Became Big-Time Weapons Traders', Rolling Stone, 16 maart 2011, http://www.rollingstone.com/politics/ news/the-stoner-arms-dealers-20110316 (geraadpleegd 12 oktober 2016). 